\title{
Fluorescence angiography of the fundus vessels in aortic coarctation
}

\author{
A. Eisalo, C. Raitta, R. Kala, and P. I. Halonen \\ From the First Department of Medicine, University Central Hospital, Helsinki; \\ and Helsinki University Eye Hospital
}

Fluorescence angiograms were performed in 25 patients with aortic coarctation. Examination of these angiograms revealed, in addition to tortuosity of the arterioles, an increased density of retinal and choroidal capillaries in the capillary filling phase. Increased density of the retinal and choroidal capillaries was found in all but one of 7 patients examined before operation. In 15 out of 18 patients examined only after operation a similar fluorescent glow was found after the successful reconstructive vascular operation, even for 10 years. All the patients without signs of increased capillarization were operated on at an advanced age.

Corkscrew-shaped tortuosity of the retinal arteries, with almost entire absence of signs of hypertensive retinopathy, have been described as the most characteristic findings in aortic coarctation (Nicolson, 1940; Rhodes and Durbin, 1942; Schwartz, 1946; Lundar, 1948; Connelly and Gibson, 1949; Granström, 1951).

Fluorescence angiography makes it possible to study the status of the retinal and choroidal vasculature including capillaries. In this report emphasis will be placed on the fundic vascular pattern in patients with aortic coarctation studied by this method.

\section{Subjects and methods}

The fundi of 25 patients with aortic coarctation were studied by fluorescence angiography. The ages of the patients ranged from 17 to 46 years. In 7 cases fluorescence angiography was performed both before and after operation. In 18 cases it was performed after successful reconstructive vascular surgery. Before fluorescence angiography, physical and ophthalmoscopic examinations were made, and serum creatinine and urinary sediment determined. The fluorescence angiograms were evaluated by the ophthalmologist, who was unaware of the history and clinical data of the patients.

Injections of 2.5-5 ml. 5 per cent fluorescein sodium were made into an antecubital vein. Fluorescence photographs were taken at intervals of 2 seconds, and a series of about 20 photographs was taken in each case. A Zeiss apparatus with an inbuilt cobalt and Wratten 47 filter and automatic recorder was used.

Received 27 May 1969.

\section{Results}

The clinical data of the patients are presented in Table I. No renal, endocrine, or other causes for the high blood pressure, except the aortic coarctation, were detected. The aortic coarctation, which was of subductal type in every case, was the only cardiovascular anomaly that could be verified during operation.

All the patients were subjectively symptom free. Serum creatinine and urinary sediment were within normal limits in every case. None of the patients was receiving any therapy.

Fluorescence angiographic findings are presented in Table 2. Seven patients ( $1,9,15$, $22,23,24$, and 25) were examined both before and after operation. Tortuosity of the retinal vessels could be demonstrated before operation in 4 of the 7 patients. The tortuosity of the vessels persisted after operation when the patients were examined 4 days to 4 months after operation. In those only examined after operation it was seen in half the cases. Arterioles as well as venules were found to be tortuous (Fig. I).

The principal finding was increased density of the capillaries. It was most clearly visible as a fluorescent glow in angiograms taken at the early venous filling phase, that is the phase when the retinal and choroidal capillaries are filled with the dye (Fig. 2a, 2b, Fig. 3). In these photographs an increased density of both retinal and choroidal capillaries could be seen. In a few of the photographs the intricate capillary patterns of retina and choroidea could be seen separately. Increased density of 
TABLE I Clinical data of 25 patients with aortic coarctation

\begin{tabular}{|c|c|c|c|c|c|c|c|c|}
\hline \multirow[t]{2}{*}{$\begin{array}{l}\text { Case } \\
\text { No. }\end{array}$} & \multirow[t]{2}{*}{ Sex } & \multirow[t]{2}{*}{$\begin{array}{l}\text { Age } \\
(y r .)\end{array}$} & \multicolumn{2}{|c|}{$\begin{array}{c}\text { Blood pressure before } \\
\text { operation } \\
(\text { mm. } H g)\end{array}$} & \multirow[t]{2}{*}{$\begin{array}{l}\text { Size of } \\
\text { coarctation } \\
(\mathrm{mm} .)\end{array}$} & \multirow{2}{*}{$\begin{array}{l}\text { Follow-up } \\
\text { period } \\
\text { after } \\
\text { operation } \\
(y r .)\end{array}$} & \multicolumn{2}{|c|}{$\begin{array}{l}\text { Blood pressure } \\
\text { after operation } \\
\quad(\mathrm{mm} . \mathrm{Hg})\end{array}$} \\
\hline & & & Arm & Leg & & & Arm & Leg \\
\hline $\mathbf{I}$ & M & 17 & $180 / 120$ & Not measurable & 5 & 2 wk. & $135 / 85$ & $155 / 120$ \\
\hline 2 & $\mathbf{M}$ & 24 & $150 / 90$ & Not measurable & 2 & 13 & $145 / 85$ & $165 / 100$ \\
\hline 3 & $\mathbf{F}$ & 31 & $170 / 90$ & $120 / 100$ & 3 & 5 & $135 / 85$ & $165 / 110$ \\
\hline 4 & $\mathbf{M}$ & 40 & $220 / 100$ & $150 / 110$ & 5 & 5 & $160 / 100$ & $210 / 110$ \\
\hline 5 & $\mathbf{M}$ & 25 & $180 / 90$ & $120 / 90$ & 2 & 10 & $155 / 80$ & $150 / 90$ \\
\hline 6 & $\mathbf{F}$ & 30 & $180 / 55$ & $120 / 90$ & 4 & 7 & $150 / 60$ & $160 / 70$ \\
\hline 7 & $\mathbf{F}$ & 27 & $225 / 85$ & $140 /-$ & 2 & ro & $180 / 95$ & $180 / 120$ \\
\hline 8 & $\mathbf{F}$ & 28 & $180 / 90$ & $120 / 100$ & 5 & 5 & $145 / 85$ & $150 / 110$ \\
\hline 9 & F & 21 & $180 / 100$ & Not measurable & 3 & 2 wk. & $120 / 100$ & $150 / 110$ \\
\hline 10 & $M$ & 25 & $160 / 110$ & $140 / 115$ & 5 & 3 & $110 / 80$ & $150 / 80$ \\
\hline II & $\mathrm{F}$ & 24 & $170 / 100$ & Not measurable & 2 & $\frac{1}{2}$ & $135 / 95$ & $155 / 100$ \\
\hline 12 & $\mathbf{M}$ & 29 & $150 / 100$ & Iro/70 & 2 & 3 & $135 / 90$ & $140 / 100$ \\
\hline 13 & $\mathbf{F}$ & 26 & $170 / 100$ & $140 / 90$ & 7 & $\mathbf{I}$ & $150 / 90$ & $130 / 90$ \\
\hline 14 & $\mathbf{M}$ & 46 & $210 / 115$ & $135 / 100$ & Not mentioned & $\mathbf{I}$ & $160 / 90$ & $150 / 100$ \\
\hline 15 & $M$ & 29 & $205 / 105$ & $601-$ & 4 & 2 wk. & $150 / 100$ & $170 / 110$ \\
\hline 16 & $\mathbf{M}$ & 29 & $180 / 110$ & Not measurable & 5 & 2 & $160 / 100$ & $175 / 120$ \\
\hline 17 & $\mathbf{M}$ & 18 & $170 / 110$ & I I $9 / 90$ & 5 & 2 & $150 / 100$ & $170 / 120$ \\
\hline 18 & $\mathbf{M}$ & 26 & $220 / 120$ & Not measurable & Not mentioned & 3 & $160 / 80$ & $160 / 100$ \\
\hline 19 & $\mathbf{M}$ & 22 & $170 / 100$ & Not measurable & 4 & I & I ro/80 & $120 / 80$ \\
\hline 20 & $\mathbf{F}$ & 38 & $160 / 80$ & $105 / 70$ & 3 & 3 & $150 / 80$ & $140 / 90$ \\
\hline 21 & $\mathbf{F}$ & 46 & $210 / 90$ & $120 / 80$ & 3 & $\frac{1}{2}$ & $150 / 80$ & $150 / 90$ \\
\hline 22 & $\mathbf{M}$ & 19 & $180 / 90$ & Not measurable & 5 & 3 wk. & $175 / 100$ & $175 / 130$ \\
\hline 23 & $\mathbf{M}$ & 40 & $185 / 120$ & Not measurable & Not mentioned & 4 dy. & $170 / 110$ & $180 / 130$ \\
\hline 24 & $\mathbf{F}$ & 17 & $120 / 80$ & Not measurable & 5 & 4 mth. & $120 / 75$ & $110 / 80$ \\
\hline 25 & $\mathbf{M}$ & 30 & $155 / 90$ & Not measurable & 2 & 2 wk. & $135 / 85$ & I70/II5 \\
\hline
\end{tabular}

TABLE 2 Fluorescein angiographic findings

\begin{tabular}{|c|c|c|c|c|c|}
\hline $\begin{array}{l}\text { Case } \\
\text { No. }\end{array}$ & $\begin{array}{l}\text { Patient's age } \\
\text { at operation } \\
(y r .)\end{array}$ & $\begin{array}{l}\text { Interval between } \\
\text { operation and } \\
\text { investigation (yr.) }\end{array}$ & $\begin{array}{l}\text { Tortuosity } \\
\text { of retinal } \\
\text { vessels }\end{array}$ & $\begin{array}{l}\text { Fluorescent } \\
\text { glow of } \\
\text { fundust }\end{array}$ & Remarks \\
\hline $\mathbf{r}$ & 17 & 2 wk. & ++ & ++ & Same findings before and after operation \\
\hline 2 & II & 13 & + & + & - \\
\hline 3 & 26 & 5 & $\mathbf{N}$ & + & - \\
\hline 4 & 35 & 5 & ++ & ++ & $\begin{array}{l}\text { Blood pressure in arm after operation } \\
160 / 100 \mathrm{~mm} . \mathrm{Hg}\end{array}$ \\
\hline 5 & I5 & ro & + & ++ & - \\
\hline 6 & 23 & 7 & $\mathbf{N}$ & + & 一 \\
\hline 7 & 17 & ro & $\mathbf{N}$ & + & Straightening and narrowing \\
\hline 8 & 23 & 5 & $\mathbf{N}$ & + & - \\
\hline 9 & 21 & 2 wk. & + & ++ & Same findings before and after operation \\
\hline Io & 22 & 3 & $\mathbf{N}$ & + & - \\
\hline II & 23 & $\frac{1}{2}$ & + & + & - \\
\hline 12 & 26 & 3 & $\mathbf{N}$ & + & Straightening and narrowing \\
\hline 13 & 25 & $\mathbf{I}$ & + & + & - \\
\hline 14 & 45 & $\mathbf{I}$ & + & $\mathbf{N}$ & - \\
\hline 15 & 29 & 2 wk. & $+t$ & ++ & Same findings before and after operation \\
\hline 16 & 27 & 2 & ++ & ++ & - \\
\hline 17 & 16 & 2 & ++ & $+t$ & - \\
\hline 18 & 23 & 3 & $\mathbf{N}$ & + & - \\
\hline 19 & 21 & I & $\mathbf{N}$ & ++ & - \\
\hline 20 & 35 & 3 & $\mathrm{~N}$ & $\mathbf{N}$ & Straightening and narrowing \\
\hline $2 \mathbf{I}$ & 45 & $\frac{1}{2}$ & ++ & $\mathbf{N}$ & - \\
\hline 22 & 19 & 3 wk. & $\mathbf{N}$ & ++ & Same findings before and after operation \\
\hline 23 & 40 & 4 dy. & $\mathbf{N}$ & $\mathbf{N}$ & $\begin{array}{l}\text { Straightening and narrowing; same find- } \\
\text { ings before and after operation }\end{array}$ \\
\hline 24 & 17 & $4 \mathrm{mth}$. & + & ++ & Same findings before and after operation \\
\hline 25 & 30 & 2 wk. & $\mathbf{N}$ & ++ & $\begin{array}{l}\text { Straightening and narrowing; same find- } \\
\text { ings before and after operation }\end{array}$ \\
\hline
\end{tabular}

«Symbols denoting degree of tortuosity of the vessels: $\mathrm{N}=$ normal, $+=$ clearly visible, $++=$ conspicuous. + Symbols denoting fluorescence of the capillaries: $\mathbf{N}=$ normal, $+=$ increased, $++=$ strongly increased. 


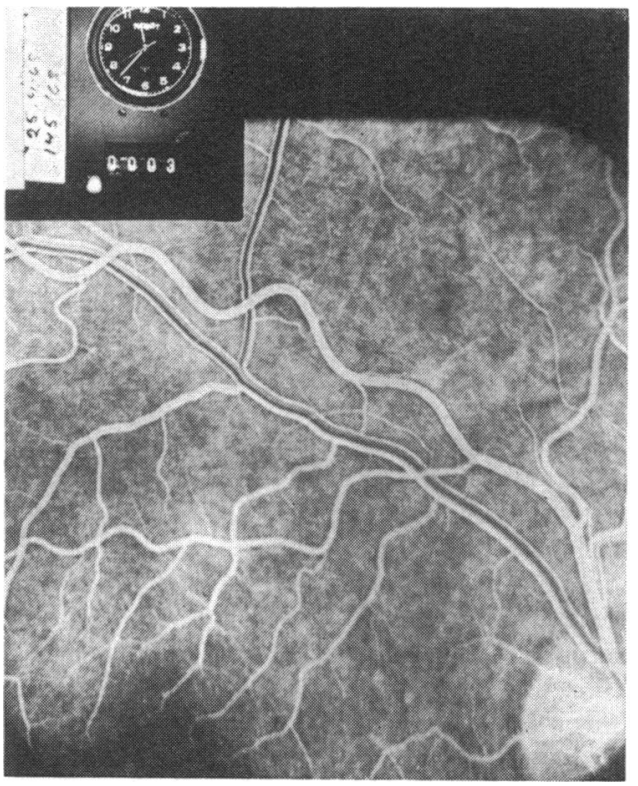

FIG. I Tortuosity of retinal vessels in a woman aged 21 years. Pre-operative picture. Blood pressure was $180 / 100 \mathrm{~mm}$. Hg in the right arm and was unmeasurable in the legs.

FIG. 2 Filled retinal capillaries in the early venous filling phase of fluorescence angiography in a man aged 29 years. Pre-operative picture. Blood pressure 205/105 mm. $\mathrm{Hg}$ in the right arm and $60 /-\mathrm{mm}$. Hg in the legs.

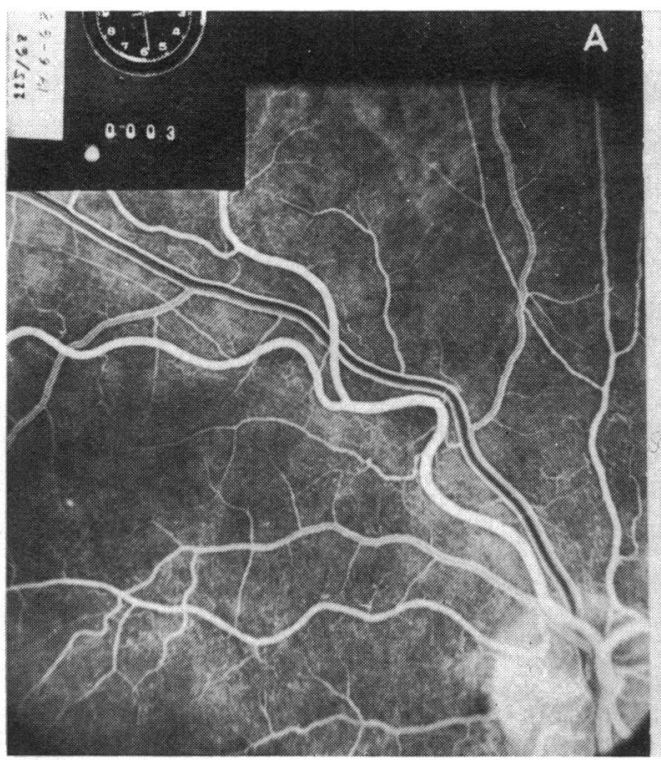

the dye was visible in 6 of the 7 patients examined before operation. The capillary overfilling persisted after operation when the patients were examined 4 days to 4 months after operation and was found in 15 of the 18 patients examined only after operation.

No haemorrhages, hard exudates, and/or micro-infarcts could be detected in any patient. Straightening and focal narrowings of arterioles were found in 5 patients, one of whom had been examined before operation by fluorescence angiography.

\section{Discussion}

Though fluorescence angiography reveals retinal vascular alterations and offers a means for examining the capillary bed, comparative estimates of normal and altered retinal and choroidal vessels in different patients are quite impossible by this method owing to the enormous individual variation in the retinal vascular pattern. Likewise, quantitative comparisons of the retinal microcirculatory patterns in different subjects are out of the question. Therefore, it was only possible to make a qualitative estimation. To ensure that the clinical data of the patients did not influence

FIG. 2b The retino-choroidal pattern 19 seconds later in the same patient. Patchy fluorescence on the background indicating overfilling of the choriocapillaris. Retinal vessels are still filled: note uneven fluorescence as well as calibre changes.

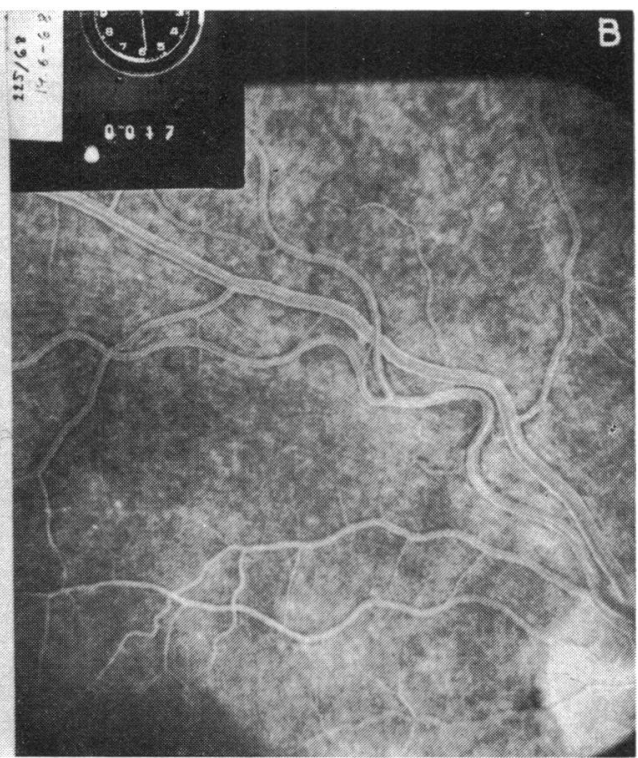




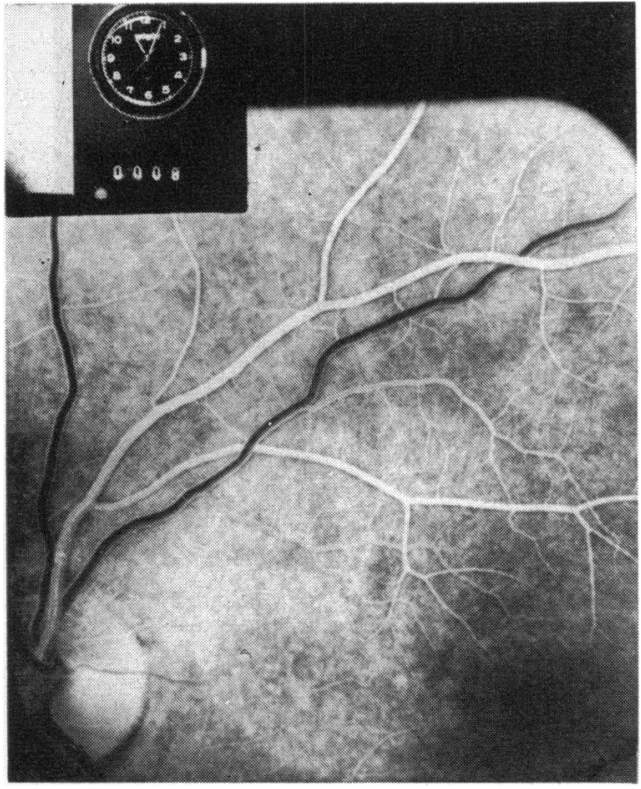

FIG. 3 Fluorescence photograph in a man of 29 years, 3 years after operation. The increased background fluorescence shows in the early venous filling phase of the angiography.

the interpretation of the angiograms, the fluorescent photographs were examined first, and the results were then correlated with the historical data and blood pressure levels of the patients.

The most typical finding in the fluorescent photographs was an increased fluorescent glow. It was most intense in the capillary filling phase, when retinal as well as choroidal capillaries were filled with the dye. It was impossible to interpret which of these two capillary beds was predominantly filled with fluorescein. The increased density of the retino-choroidal network was found more often than tortuosity in the retinal vessels. As retinal and choroidal capillarization develops during foetal life or during the perinatal period (Michaelson, 1954; Henkind and De Oliveira, 1967; Shakib, De Oliveira, and Henkind, 1968), the increased meshwork may form at the same time, because signs of neovasculogenesis (e.g. newly formed vessels) were absent in every case.

The origin of vasculogenic cells in the retina is not yet fully explained (Ashton, 1954; Michaelson, 1954; Cogan, 1963; Shakib et al., 1968). No other factors leading to the formation of capillaries are known. It may be assumed that in aortic coarctation one of the stimuli leading to proliferation of the capillary meshwork in the choroidea and retina is the existence from foetal life of an abnormal intraarterial pressure above the constriction. However, it is difficult to decide whether the high blood pressure is the prime factor, because, as far as we know, no similar choroidal and retinal alterations are seen in any other form of hypertension.

Only in 4 cases was there no evidence of increased fluorescence in the angiograms. One patient (Case 23) was examined before and after operation. All these 4 patients were operated on at advanced ages (35-45 years). On the other hand, the time elapsing between the operation and the examination did not differ from that of the other patients.

Furthermore, in 2 of these 4 patients focal narrowing and/or straightening of the retinal vessels could be detected, i.e. vascular alterations that were similar to those seen in benign hypertension. Because of the relatively advanced age at the time of the operation, the blood pressure had been high for a long time, the course resembling that of benign hypertension. However, it has been emphasized that in aortic coarctation signs of hypertensive retinopathy are almost entirely lacking (Granström, 195I). Moreover, in one patient in this series, with straightening and focal narrowing of the retinal vessels and with a normal fluorescence pattern in angiograms, the blood pressure in the arms before operation was almost normal (160/80 $\mathrm{mm}$. $\mathrm{Hg})$. Thus, the only characteristic common to these 4 patients with a normal fluorescence pattern is their greater age, which is also reflected in the fluorescence photographs as local morphological degenerative changes in the vascular walls.

The study was supported by a grant from Paulo Foundation.

Ashton, N. (1954). Pathological basis of retrolental fibroplasia. British fournal of Ophthalmology, 38, 385.

Cogan, D. G. (1963). Development and senescence of the human retinal vasculature. Transactions of the Ophthalmological Society of the United Kingdom, 83, 465 .

Connelly, B. W., and Gibson, G. G. (1949). The retinal arterioles in coarctation of the aorta; 14 -year observation of a case. American fournal of Ophthalmology', 32, 1513 .

Granström, K. O. (195I). Retinal changes in coarctation of the aorta. British fournal of Ophthalmology, 35, 143 .

Henkind, P., and De Oliveira, L. F. (1967). Development of retinal vessels in the rat. Investigative Ophthalmology, 6, 520 .

Lundar, J. (1948). Coarctatio aortae. Nordisk Medicin, 39, 1657. 
Michaelson, I. C. (1954). Retinal Circulation in Man and Animals. Charles C. Thomas, Springfield, Illinois.

Nicolson, G. H. B. (1940). Coarctation of the aorta in a child with arrested subacute bacterial endarteritis and a calcified myotic aneurysm at the seat of stricture. American Heart fournal, 20, 357.

Rhodes, P. H., and Durbin, E. (I942). Coarctation of the aorta in childhood; review of the literature and report of 3 cases. American Fournal of Diseases of Children, 64, 1073.

Schwartz, R. (1946). Coarctation of the aorta; a report of 5 cases. New York State fournal of Medicine, 46, 739.

Shakib, M., De Oliveira, L. F., and Henkind, P. (1968). Development of retinal vessels. II. Earliest stages of vessel formation. Investigative Ophthalmology, 7, 689. 